\title{
A Proposed Model of Intercultural Communication Competence (ICC) in Malaysian Context
}

Muhammad Umar NADEEM ${ }^{1}$, Rosli MOHAMMED ${ }^{2}$, Syarizan DALIB ${ }^{3}$

\begin{abstract}
ARTICLE INFO
ABSTRACT

Article History:

Received

10.04.2017

Received

in

revised form

25.05.2017

Accepted

Available online

01.01.2017

The basic determination for this paper is to throw light on the culture general models of intercultural communication competence (ICC). Furthermore, to propose a culture general model for Malaysian context in the presence of religiosity. It is suggested by the previous researchers to refine these models by adding variables in them. Ministry of Higher Education of Malaysia is hosting huge number of international students in their institutions and have plans to host maximum from the whole world. Religion is the key element of intercultural interactions in Malaysia. Therefore, a research on the international students in the context of religion would provide the better understanding and application of culture general model of ICC in Malaysian context. As well as, it will provide valuable findings that depicts to what extent the religiosity of international students enables them to be competent in intercultural communication.
\end{abstract}

(C) 2017 IJERE. All rights reserved

\section{Keywords:}

Intercultural Communication Competence (ICC), Religion, Religiosity.

\section{INTRODUCTION}

The consensus of the well-known researchers regarding the definition of intercultural competence is missing (Deardorff, 2006; Fantini, 2000; Rathje, 2007; Spitzberg \& Changnon, 2009). There is the diversity of definitions about the basic concepts like communication, culture, competence, intercultural as well as the skills and abilities that are noticed as vital intercultural competence (Spitzberg \& Changnon, 2009). There is no mutual consent regarding any particular description of ICC, there is only a diversity of models on different features and describe intercultural competence another way (Rathje, 2007).

Spitzberg and Cupach (1984) states intercultural competence like performance which requires to be effective in addition to appropriate. Appropriateness refers to the right and correct communication during the interaction inside a specific culture (Wiseman \& Koester, 1993). On the other hand, Effective communication or behavior is the ability to achieve personal goals by manipulating and controlling one's environment (Wiseman, 2002). Steinberg (2007) enhances that it is not a normal thing to be a competent communicator, on the other hand like the extra ability, that could be learned. Competent communicators among the people, it is obligatory they must be interested, besides having aspiration to obtain this essential understanding plus expertise (Gudykunst, 2002). In Deardorff (2006) investigation, intercultural scholars were the sources of data collection in Delphi study, the popular description from between nine descriptions of

\footnotetext{
${ }^{1}$ Corresponding e-mail: umarnadeemx@gamil.com Universiti Utara Malaysia ${ }^{1}$, Universiti Utara Malaysia ${ }^{2}$ Universiti Utara Malaysia ${ }^{3}$
} 
intercultural competence be there "the ability to communicate effectively and appropriately in intercultural situations based on one's intercultural knowledge, skills, and attitudes" (pp. 247-248).

The concept of intercultural communication competence (ICC) has been studied through various theoretical lenses. Some of the well-known models of ICC in the intercultural communication literature are the Anxiety/Uncertainty Reduction Model (Gudykunst, 1993, 1995, 2002; Stephan, Stephan, \& Gudykunst, 1999); the Identity Negotiation Model (Ting-Toomey, 1993); and Spitzberg (1997) model of ICC. This is through no means a comprehensive slant. On the other hand, there are very few culture general model which has been developed so far in a setting which is dominated by the west (Arasaratnam, 2006; Arasaratnam \& Banerjee, 2007, 2011; Arasaratnam, Banerjee, \& Dembek, 2010a, 2010b). The purpose of this study is to do detailed review of culture general models of ICC and enhance the recent model of ICC developed by Arasaratnam and Banerjee (2011) by adding religiosity variable according to the context of Malaysia.

According to Deputy Prime Minister of Malaysia that by 2020, Ministry of Higher Education targets to host as a minimum 200,000 students from all over the world for Malaysia (Chi, 2011). Middle Eastern African states, Southeast Asia, Middle Eastern states, and Middle Asia, and a nominal figure from Europe are the basic sources of international students heading to Malaysia for higher studies (Mahmud, Amat, Rahman, \& Ishak, 2010). The impact of 9/11 has witnessed a decline of new applicants from the Middle Eastern Countries in the United States. Students are reluctant to further their studies in the US and alternatively sought their further education in other countries like Malaysia (Sirat, 2008).

Mahmud et al. (2010) stated that Islamic religion and Asian culture have a strong influence on the Malaysian culture. The culture of Malaysia is slightly different from the other Muslim countries. The foreigners are treated on the basis of their religion because the religion is not a personal matter in Malaysia (Mamman, 1995). In western culture, religion is not having a significant impact on intercultural competence. But in Malaysia, religion plays vital role in intercultural interactions. A study by Nadeem, Mohammed, and Dalib (2017) strongly recommends to address religiosity in the context of Malaysia on the international students.

Ameli and Molaei (2012) demonstrates that religious affiliation can affect the intercultural communication among the individuals of Iran. Wrench, Corrigan, McCroskey, and PunyanuntCarter (2006) demonstrated that religion is an essential constituent in the learning of intercultural communication. This is the zone that is still disposed for investigation scrutiny and recommended that additional communication researchers would look at the necessity to inspect how religion and intercultural competence interconnect from an empirical perspective. Holmes and O'Neill (2012) strongly recommends religious identities and positions of faith have impact on intercultural competence and the factor religion needed further empirical investigation. In this study, religiosity is treated as the role of religion in intercultural competence.

Several researches suggest that models of ICC need further exploration among different cultures and further research is required to test and to enhance the model further by adding variables (Arasaratnam, 2004, 2005; Arasaratnam \& Banerjee, 2007, 2011; Arasaratnam et al., 2010a, 2010b).

There are limited models who have been addressed in the West (Arasaratnam, 2006; Arasaratnam \& Banerjee, 2007, 2011; Arasaratnam et al., 2010a, 2010b) but, it is too difficult to find a culture general model that has been addressed in non-western context especially in Malaysia. The conceptual framework of the study is quite different from the previous models and unique as well. Because, the previous models have not considered or overlooked the importance of 
religiosity in the models of ICC. This conceptual framework added religiosity due to its importance in intercultural competence.

The prime objective for this research is to propose a model of ICC specifically for the Malaysian context.

\section{Review Of Literature}

\section{Culture}

Williams (2014) said that "Culture is one of the two or three most complicated words in the English language" (p. 87). Usually the culture is perceived from different perspective according to discipline due to the diversity of ideas in the culture as well as in the nature (Moran \& Lu, 2001). That's the reason why the literature is having a lot of definitions regarding culture.

Rendering to Samovar, Porter, McDaniel, and Roy (2015), five key features of culture by which one can easily distinguish it from others. These features are social organizations, history, language, values and religion. History of the culture helps the individuals to shape up their identity as well as their behavior. Religion can influence in every feature of the culture, and the suitable ways of behaving depends upon the the values of the specific culture. Culture can be reflected through the social organizations which are government and the family, and the last feature language permits the culture to occur by helping its transmission.

\section{Intercultural Communication}

Allwood (1985) discussed that intercultural communication is basically the exchange of information between the individuals from the diverse cultural backgrounds, dissimilar parameters of control and changed levels of awareness. Ting-Toomey and Kurogi (1998) believed that intercultural communication is the symbolic conversation besides negotiation of collective result during the communication of the individuals from the diverse cultural backgrounds. Bennett (1986) defined intercultural communication as the ability to understand dissimilar ways and patterns of communication for instance, norms or values, verbal/nonverbal communication and the gestures of individuals.

Intercultural communication is considered as the skill of interaction appropriately and having a shared understanding among the individuals who are culturally different, it is very necessary to have an understanding of our own culture, and attempt for looking at the similarities as well as the differences among the cultures (Bennett, 1986; Klein \& Chen, 2001). One can head to intercultural competence by simply accepting and appreciating the similarities and the differences of the other cultures.

\section{Intercultural Competence}

Competency is all about the "an ability to perform satisfactorily, the task being clearly defined and the criteria of success being set out alongside" (Zimmermann, 2010). Rendering to Fantini and Tirmizi (2006) every individual has ability to enhance their communicative competence according to their local language which usually helps them to head towards the communication with in similar cultures without any confusions. On the other hand, when the individual requires an interaction with the culturally different people having different language. Then, that individual needs to learn that language. For this novel condition that individual have to initiate additional communicative competence, which is termed as "intercultural" communicative competence (Fantini \& Tirmizi, 2006).

Intercultural competence coupled with the individuals' discourse, linguistics and sociolinguistic competence which forms intercultural communicative competence (Byram, 1997). 
Individual can connect the awareness of other cultures in the linguistic competency in the form of skills to utilize linguistic appropriately to be competent in intercultural communication.

The most familiar explanations about the competence mentioned that it is the capacity to inculcate linguistic skills in different scenarios. Seiler and Beall (2002) explained that competency in communication is refer to the ability to take part in effective communication which is mostly demonstrated by awareness and the skills which allows individuals to share information fruitfully. Due to globalization, industries have requirement from their workers that they have efficient speaking and writing power across different cultures to gain their agenda. McCain (1996) intensely confirms that communication competency is an essential apprehension for interaction or dialogue.

\section{Culture General Models of Intercultural Communication Competence}

Arasaratnam and Doerfel (2005) provide research as an illustration to research ICC in culture general perspective. The research subjects of the study were questioned by the authors to describe ICC by their own means, 15 countries got representation by the 37 individuals in the study. The dominant themes about these descriptions were identified by the semantic network analysis. After analysis five variables were appeared, motivation, experience in intercultural communication, ability to listen, empathy with the individuals that belong as of different cultures and positive attitude towards the people from other cultures. That was the fresh kind of existence of a new model about ICC. The outcomes were encouraging but there is still lacking concerning its testing extensively.

\section{Further Testing of a New Model of Intercultural Communication Competence}

Grounded on the findings about the previous researches (Arasaratnam, 2004; Arasaratnam \& Doerfel, 2005) in the arena of intercultural competence a fresh model of ICC stood developed to find out certain variables contribute to ICC. Arasaratnam (2006) developed a new model to respond the limits of earlier researches. Statistics was composed by survey technique and used regression analysis. There were key five variables that appeared after the explanations of the research subjects in the initial scholarship were attitude toward other cultures, experience, motivation, listening (interaction involvement) and empathy. Outcomes exposed a positive correlation among cultural empathy and interaction involvement, interaction involvement plus attitude toward other cultures, cultural empathy also attitude toward other cultures, experience and attitude toward other cultures, motivation and attitude toward other cultures, confident association among experience in addition to motivation, interaction involvement and ICC, motivation and ICC, and empathy plus ICC. However, the researchers found an insignificant relationship among motivation and interaction involvement. Furthermore, cultural empathy and intercultural experience was also having a negative association. The study was focused only on Caucasian American. The results were promising and it was recommended by the researcher to apply this model on different cultural backgrounds.

\section{Ethnocentrism and Sensation Seeking as Variables that Influence Intercultural Contact-Seeking Behavior}

Another study that was conducted by Arasaratnam and Banerjee (2007) to find out sensation seeking and ethnocentrism as the forecaster of intercultural contact pursuing behavior. Relationship of the variables was proposed in the form of paths and measured by the regression analysis. Regression exposed a straight positive correlation among sensation seeking as well as motivation, social initiative and motivation, along with sensation seeking and social initiative. On the contrary, a negative correlation was witnessed between ethnocentrism and other variables, such as motivation, social initiative, and intercultural friends. The association among motivation and intercultural friends was appeared to be insignificant in nature. The results suggest that 
ethnocentrism may also hinder the sensation seekers from forming intercultural friendship and weaken the motivation of the individual to intermingle through the individuals of diverse cultural experiences. That model gave the better understanding that predict intercultural contact seeking behavior. This scholarship was directed on the students with diverse cultural backgrounds of America.

\section{The Integrated Model of Intercultural Communication Competence}

The Integrated Model of Intercultural Communication Competence (IMICC) was the other established model of ICC which comprises of different culture and known as the model of general cultures. Arasaratnam and more than a few co-authors finished an age of some years to establish this model, among 2003 to 2011. The undeveloped organization the IMICC previously established during 2003, once Arasaratnam and Doerfel (2005) directed the quantitative scholarship towards the progress of novel model of ICC. The particular model was characterized as IMICC (Arasaratnam et al., 2010a).

Conferring to Arasaratnam et al. (2010a) this IMICC is distinctive as well as dissimilar among rest of the ICC models for the reason that of its progress from an emic methodology, its culturegeneral manner, and an extremity style. The extremity style in this setting suggests the inspection of a wonder from the insider's opinion as well as determining in its place of emerging vital extents (Morris, Leung, Ames, \& Lickel, 1999; Sinicrope, Norris, \& Watanabe, 2007). It was the model who attempts " to investigate the identity and nature of the variables that contribute towards ICC" (Arasaratnam \& Doerfel, 2005). IMICC comprises of five potentials that would be placed in additional facet in the subsequent section.

The IMICC entails of five potentials. In 2003, these potentials were recognized by research subjects from the initial scholarship of the IMICC. Variables like global attitude or positive attitude towards people from other cultures (ATOC), motivation, the empathy and ability to listen. Initially, IMICC was having the variable named experience, but it was swapped with another variable in the upcoming researches. Sensation seeking took the place of this variable.

Empathy described as "an individual's ability to engage in cognitive and emotional role taking and to adapt his or her behavior appropriately to the situation" (Arasaratnam, 2004). The vicarious person is capable to perform (apparent) proficient performances, involve in actions which affect other individuals, as well as capable to place himself/herself at the lower states of other thoughts (Arasaratnam, 2004).

Motivation was well-defined as the aspiration to participate in intercultural interactions for the determination of learning and understanding about other cultures (Arasaratnam, 2004). Arasaratnam (2006) further states that motivation is "the desire to engage in intercultural interactions for understanding and learning about other cultures" (p. 94).

ATOC otherwise global attitude defines a person's directness for concerning new cultures besides worldviews (Arasaratnam, 2004). A person besides international approach has "positive attitudes towards people of other cultures and is not ethnocentric" (Arasaratnam, 2004).

The ability to listen fine besides providing courtesy, also described as communication participation, labels "the extent of one's cognitive and behavioral engagement in conversation" (Arasaratnam, 2004). A person with the capability to pay attention fine should be capable for understanding vigorously as well as comprehend other's requirements.

Intercultural experience was recognized as the variable from the research subjects as the essential sign about suitable extra proficient (Arasaratnam, 2004). That comprised of capability of the person to absorb starting practice then acclimate his/her actions. Nevertheless, IMICC 
eradicated this variable from the further studies for the reason that it demonstrated problems to estimate the effect of intercultural practice on a person's ICC (Arasaratnam et al., 2010b).

Whereas presence of the behavior variable, "one of the key players in ICC" sensation seeking was added by Arasaratnam et al. (2010b). In the scholarship, writers establish that sensation seeking was completely connected with the approaches concerning the individuals from new cultural backgrounds besides sympathy. Sensation seeking was categorized as "the need for novelty, excitement and adventure, as well as with a low attention span" (Zuckerman, 1994) and is chiefly acknowledged in medical scholarships, particularly as a predilection variable associated to dangerous activities for example medication plus liquor misuse, then similarly dangerous games (Arasaratnam \& Banerjee, 2011; Arasaratnam et al., 2010b). Though, Morgan and Arasaratnam (2003) establish that sensation seeking would never merely connected by hazardous activities nonetheless likewise through necessary public activities for instance participating in intercultural relationships. Arasaratnam (2005) originate that sensation seeking look as if rise interaction search for activities with individuals belongs to different cultural backgrounds. Arasaratnam et al. (2010b) claim the perception of intercultural understandings represents the newness which sensation seekers are strained for.

The IMICC was established and nonstop accustomed all over numerous scholarships. Study 1 was the best central one, because the primary construction of the model utilized the materials about the diverse skills of the individuals. That scholarship directed by the Arasaratnam and Doerfel in 2005. The objective of writers was to form a culture-general model which was theoretically comprehensive (Arasaratnam \& Doerfel, 2005). The researchers allow the research subjects to explain the skills rather than providing the depiction about the skills from their side. They illustrated by Bruner's (1990) impression about collective denotation of culture, in which it was suggested about the existence of collective denotation in one segment, in this case intercultural competence, between participants having similar cultural values. So, inquiring participants from diverse values concerning awareness about intercultural competence might head for gathering the significant appearances. The writers selected that particular tactic for the reduction of investigator's power besides for the reason that the researcher superior knows the culture marvel (Arasaratnam et al., 2010a; Arasaratnam \& Doerfel, 2005).

Arasaratnam and Doerfel (2005) questioned participants of diverse cultures to gather the opinion about intercultural competence. That phenomenological scholarship was directed between 37 students of America as well as worldwide learners plus natives over unrestricted conversations. The members were repeatedly complicated in intercultural communication. About that investigation writer's castoff, a SEM approach for data analysis. In command towards highlight position about professed ICC no private gossips were castoff. The subsequent queries provided to all the members: In what way, you describe intercultural communication? Could you classify roughly abilities otherwise features about individuals who are capable in intercultural communication? Could you recognize few precise people whom you consider are predominantly competent in intercultural communication besides at a guess why you remark them intrinsically? What are characteristics of decent communication in your philosophy/estimation? What are features of ruthless communication in your philosophy/estimation? (Arasaratnam \& Doerfel, 2005).

Furthermore, writers differentiated five dissimilar abilities about the worthy speaker which are the global attitude (ATOC), motivation, earlier intercultural experience/training, capability to hear sound during dialogue and empathy (Arasaratnam \& Doerfel, 2005).

Next succeeding scholarships were directed through dissimilar academia of Australia as well as USA. Aimed remain same for every scholarship were to more examine the five potentials, the relationship among them, in addition to the organization of model. Australia was the well 
experience of IMICC to discover the model's efficacy among diverse cultural setting (Arasaratnam et al., 2010a). Sensation seeking replaced the experience due to its superiority (Arasaratnam et al., 2010b).

At last, the IMICC is a model comprises of many cultures about ICC that was established over a different style. That style endorsed the investigators to gather views around professed ICC. The IMICC was made complete on quantitative scholarship as compared to the rest of the models. The five potentials shaped that theoretic groundwork of the model (Arasaratnam et al., 2010b). The IMICC correspondingly was continuously established, verified, in addition to attuned, to facilitate practice was promptly acknowledged by Arasaratnam and Doerfel (2005), was eradicated also swapped by sensation seeking. The five potentials are measured over and done with changed scales, and Arasaratnam (2009) established a ICC scale to quantify affection, behavior as well as cognition.

\section{Sensation Seeking and the Integrated Model of Intercultural Communication Competence}

On the similar line of research a new model was developed by Arasaratnam et al. (2010b). This model was basically a continuity of previous researches on ICC culture general models (Arasaratnam, 2004, 2006; Arasaratnam et al., 2010a). It was explored the correlation among sensation seeking besides other variables that usually donate to intercultural communication competence within the framework of Integrated Model of Intercultural Communication Competence (Arasaratnam et al., 2010b). Structural Equation Modeling was utilized to derive the results. Even though it was encountered an association of ICC and sensation seeking in the existence of different mediating variables but there was no straight correlation among ICC and sensation seeking. The participants were equally national as well as international students from the big institution of Australia. Lastly, recommends that this stripe of investigation is till now in initial phases and needs further purification.

\section{Sensation Seeking and Intercultural Communication Competence}

According to the results of the previous line of researches about ICC (Arasaratnam, 2006; Arasaratnam \& Banerjee, 2007; Arasaratnam et al., 2010a, 2010b). A new model was tested by Arasaratnam and Banerjee (2011), which was focused on the relationship of sensation seeking in the attendance of mediating variables attitude towards other culture as well as motivation with ICC. Motivation was positively linked through sensation seeking, which in sequence was positively linked to ICC and ATOC. Lastly, ICC positively show a relationship with ATOC. Consequently, ICC incidentally relates to sensation seeking over the mediation of ATOC and motivation. Ethnocentrism was adversely associated with sensation seeking, which additional adversely linked with ATOC, ICC and motivation. Ethnocentrism was introduced in that model which results to negative relationship with ICC. ICC was positively linked with sensation seeking in addition to other variables. Participant's data was gathered by survey method and structural equation modeling was performed. And the participants were from the the native university of Australia.

\section{RESULT, DISCUSSION, AND SUGGESTIONS}

Based on the above discussed literature, it is noticed that very few empirical models of ICC has been developed and addressed so far in the West (Arasaratnam, 2006; Arasaratnam \& Banerjee, 2007, 2011; Arasaratnam et al., 2010a, 2010b). These models are claimed to be the culture general models of ICC. It is very hard to find such models who are developed or addressed in the non-western setting especially in Malaysia. Thus, it is itself a knowledge gap that there are very few models and their testing have been done in the western setting. 
This research targets to explore the relationship of intercultural communication competence along with the different variables in a Malaysian context. Based on the model developed in the past by Arasaratnam and Banerjee (2011), this research emphasis on the international students who are studying in Malaysia and having same religious affiliations besides that the religiosity affects their intercultural interactions in daily routine matters. Although, Malaysia is having a wide range of international students but still they are facing problems which directly leads to their communication. Religion is the important part of intercultural competence should be investigated in Malaysian context. It is worthy to investigate international students' intercultural competency from a Non-Western setting in the presence of religion.

\section{Suggestions for Future Research}

It is recommended to focus on the recent model by Arasaratnam and Banerjee (2011) as the base model for the upcoming researchers. Because this model is still having lacking in it. One of the major problem is that it is tested in the west with the individuals of diverse cultural experiences specifically on the international students of America and Australia. But for the new researchers it would be useful to test this model by adding other contributor to ICC (like religiosity) in Malaysian context and the results would be totally different from its initial test. Furthermore, there is a lacking demographic variable which is religion and it is absent in this model because it has been tested in Australia and they are having other contributors to ICC instead of religion. But in the context of Malaysia, religion plays a crucial role in culture as well as in intercultural communication competence. Lastly, a research remarking these issues puts forward to ongoing efforts to solve all these issues of this model especially on international students who are studying in Malaysia.

\section{REFERENCES}

Allwood, J. (1985). Intercultural communication. Papers in anthropological linguistics, 12, 1-25.

Ameli, S. R., \& Molaei, H. (2012). Religious affiliation and intercultural sensitivity: Interculturality between Shia \& Sunni Muslims in Iran. International Journal of Intercultural Relations, 36(1), 31-40.

Arasaratnam, L. A. (2004). Intercultural communication competence: Development and empirical validation of a new model. Paper presented at the annual meeting of the International Communication Association.

Arasaratnam, L. A. (2005). Sensation seeking and international students' satisfaction of experiences in the United States. Journal of Intercultural Communication Research, 34(3), 184-194.

Arasaratnam, L. A. (2006). Further testing of a new model of intercultural communication competence. Communication Research Reports, 23(2), 93-99.

Arasaratnam, L. A. (2009). The development of a new instrument of intercultural communication competence. Journal of Intercultural Communication(20).

Arasaratnam, L. A., \& Banerjee, S. C. (2007). Ethnocentrism and sensation seeking as variables that influence intercultural contact-seeking behavior: A path analysis. Communication Research Reports, 24(4), 303-310.

Arasaratnam, L. A., \& Banerjee, S. C. (2011). Sensation seeking and intercultural communication competence: A model test. International Journal of Intercultural Relations, 35(2), 226-233.

Arasaratnam, L. A., Banerjee, S. C., \& Dembek, K. (2010a). The integrated model of intercultural communication competence (IMICC): Model test. Australian Journal of Communication, 37(3), 103. 
Arasaratnam, L. A., Banerjee, S. C., \& Dembek, K. (2010b). Sensation seeking and the integrated model of intercultural communication competence. Journal of Intercultural Communication Research, 39(2), 69-79.

Arasaratnam, L. A., \& Doerfel, M. L. (2005). Intercultural communication competence: Identifying key components from multicultural perspectives. International Journal of Intercultural Relations, 29(2), 137-163.

Bennett, C. I. (1986). Comprehensive multicultural education: Theory and practice (N. T. B. New Brunswick Ed.): Allyn and Bacon Boston.

Byram, M. (1997). Teaching and assessing intercultural communicative competence: Multilingual Matters.

Chi, M. (2011). Government aims to attract 200,000 international students by 2020. Malaysian Insider.

Deardorff, D. K. (2006). Identification and assessment of intercultural competence as a student outcome of internationalization. Journal of Studies in International Education, 10(3), 241-266.

Fantini, A. E. (2000). A central concern: Developing intercultural competence. About our institution, $25-42$.

Fantini, A. E., \& Tirmizi, A. (2006). Exploring and assessing intercultural competence.

Gudykunst, W. B. (1993). Toward a theory of effective interpersonal and intergroup communication: An anxiety/uncertainty management (AUM) perspective.

Gudykunst, W. B. (1995). Anxiety/uncertainty management theory. Intercultural communication theory, 8-58.

Gudykunst, W. B. (2002). Handbook of international and intercultural communication: Sage.

Holmes, P., \& O'Neill, G. (2012). Developing and evaluating intercultural competence: Ethnographies of intercultural encounters. International Journal of Intercultural Relations, 36(5), 707-718.

Klein, M. D., \& Chen, D. (2001). Working with children from culturally diverse backgrounds: Cengage Learning.

Mahmud, Z., Amat, S., Rahman, S., \& Ishak, N. M. (2010). Challenges for international students in Malaysia: Culture, climate and care. Procedia-Social and Behavioral Sciences, 7, 289-293.

Mamman, A. (1995). Socio-biographical Antecedents of Intercultural Effectiveness: The Neglected Factors1. British Journal of Management, 6(2), 97-114.

McCain, B. (1996). Multicultural team learning: an approach towards communication competency. Management Decision, 34(6), 65-68.

Moran, P. R., \& Lu, Z. (2001). Teaching culture: Perspectives in practice: Heinle \& Heinle Boston, MA.

Morgan, S., \& Arasaratnam, L. (2003). Intercultural friendships as social excitation: Sensation seeking as a predictor of intercultural friendship seeking behavior. Journal of Intercultural Communication Research, 32(3/4), 175-186.

Morris, M. W., Leung, K., Ames, D., \& Lickel, B. (1999). Views from inside and outside: Integrating emic and etic insights about culture and justice judgment. Academy of Management Review, 24(4), 781-796.

Nadeem, M. U., Mohammed, R., \& Dalib, S. (2017). Religion and Intercultural Communication Competence. Journal of Philosophy, Culture and Religion, 28(3), 25-29.

Rathje, S. (2007). Intercultural competence: The status and future of a controversial concept. Language and intercultural communication, 7(4), 254-266.

Samovar, L. A., Porter, R. E., McDaniel, E. R., \& Roy, C. S. (2015). Communication between cultures: Nelson Education.

Seiler, W. J., \& Beall, M. L. (2002). Communication: Making Connections.

Sinicrope, C., Norris, J., \& Watanabe, Y. (2007). Understanding and assessing intercultural competence: A summary of theory, research, and practice (technical report for the foreign 
language program evaluation project). University of Hawai'I Second Langauge Studies Paper 26 (1).

Sirat, M. (2008). The impact of September 11 on international student flow into Malaysia: Lessons learned. IJAPS, 4(1), 80-95.

Spitzberg, B. H. (1997). A model of intercultural communication competence. Intercultural communication: A reader, 9, 375-387.

Spitzberg, B. H., \& Changnon, G. (2009). Conceptualizing intercultural competence. The SAGE handbook of intercultural competence, 2-52.

Spitzberg, B. H., \& Cupach, W. R. (1984). Interpersonal communication competence (Vol. 4): SAGE Publications, Incorporated.

Steinberg, S. (2007). An introduction to communication studies: Juta and Company Ltd.

Stephan, W. G., Stephan, C. W., \& Gudykunst, W. B. (1999). Anxiety in intergroup relations: A comparison of anxiety/uncertainty management theory and integrated threat theory. International Journal of Intercultural Relations, 23(4), 613-628.

Ting-Toomey, S. (1993). Communicative resourcefulness: An identity negotiation perspective. Intercultural communication competence, 17, 72-111.

Ting-Toomey, S., \& Kurogi, A. (1998). Facework competence in intercultural conflict: An updated face-negotiation theory. International Journal of Intercultural Relations, 22(2), 187-225.

Williams, R. (2014). Keywords: A vocabulary of culture and society: Oxford University Press.

Wiseman, R. L. (2002). Intercultural communication competence. In W. B. Gudykunst, \& B. Mody (Eds.). Handbook of international and intercultural communication, 207-224.

Wiseman, R. L., \& Koester, J. (1993). Intercultural communication competence: Sage Newbury Park, CA.

Wrench, J. S., Corrigan, M. W., McCroskey, J. C., \& Punyanunt-Carter, N. M. (2006). Religious fundamentalism and intercultural communication: The relationships among ethnocentrism, intercultural communication apprehension, religious fundamentalism, homonegativity, and tolerance for religious disagreements. Journal of Intercultural Communication Research, 35(1), 23-44.

Zimmermann, K. (2010). Intercultural competence as a succes factor of virtual multicultural teams: a case study on the team effectiveness of global HR teams.

Zuckerman, M. (1994). Behavioral expressions and biosocial bases of sensation seeking: Cambridge university press. 